'Московский государственный университет имени М.В. Ломоносова, Москва

${ }^{2}$ Национальный медицинский исследовательский центр эндокринологии, Москва

ОБОСНОВАНИЕ. Сахарный диабет (СД) приводит к нарушению процессов репарации кожи, однако ведущие механизмы этой патологии до настоящего времени не выделены. В связи с этим в своей работе мы решили проверить, влияет ли гипергликемия на процесс изменения фенотипов кератиноцитов в ходе ранозаживления.

ЦЕЛЬ. Изучить влияние гипергликемии на заживление раны и дифференцировку кератиноцитов в модели стрептозотоцин-индуцированного сахарного диабета крысы.

МЕтоДЫ. У крыс вызывали развитие СД (стрептозотоцин, 65 мг/кг, внутрибрюшинно, однократно). Рану наносили в надлопаточной области на 42-е сутки, после чего через 8, 16 и 24 сут оценивали процесс репарации с помощью гистологических методов. Иммуногистохимическим методом изучали экспрессию цитокератинов 10 и 17.

РЕзУЛЬТАТЫ. У крыс с СД по сравнению с контрольной группой заживление ран замедлилось на поздних этапах. В целом заживление раны сопровождалось повышением экспрессии цитокератина 10 в ее крае по сравнению с интактной кожей, у крыс с СД была нарушена активация контрактильного фенотипа кератиноцитов.

ЗАКЛЮЧЕНИЕ. Гипергликемия в небольшой степени замедляет ранозаживление у крыс, препятствуя активации сократимых кератиноцитов.

КЛЮЧЕВЫЕ СЛОВА: сахарный диабет; стрептозоточин; репарация; заживление раны; иммуногистохимия; иитокератин 10; иитокератин 17

\title{
KERATINOCYTES DIFFERENTIATION AND WOUND HEALING IN RATS WITH STREPTOZOTOCIN - INDUCED DIABETES AND SEVERE HYPERGLYCEMIA
}

\author{
(c) Evgenii V. Ivanov', Maria P. Morozova', Ekaterina M. Rzhavina', Anna M. Gorbacheva², Svetlana A. Gavrilova', \\ Aleksei K. Erdiakov', Gagik R. Galstyan², Vladimir B. Koshelev
}

${ }^{1}$ M.V. Lomonosov Moscow State University, Moscow, Russia

${ }^{2}$ Endocrinology Research Centre, Moscow, Russia

BACKGROUND: Diabetes mellitus leads to disruption of the skin repair processes, but the leading mechanisms of this pathology have not yet been identified. In this regard, in our work, we decided to check how hyperglycaemia affects the process of keratinocyte phenotype changes during wound healing.

AIMS: To study the effect of hyperglycaemia on wound healing and differentiation of keratinocytes in a rat streptozotocin-induced diabetes model.

MATERIALS AND METHODS: Diabetes mellitus was induced in rats by using streptozotocin, 65 mg / kg, intraperitoneally, once. The wound was applied in the supra-scapular region on the 42nd day, after which (after 8, 16, and 24 days) the repair process was evaluated using histological methods. Immunohistochemistry was used to evaluate the expression of cytokeratin-10 and cytokeratin-17.

RESULTS: In rats with diabetes mellitus, wound healing slowed down in the later stages, compared with the control group. In general, wound healing was accompanied by an increase in the expression of cytokeratin-10 in its region compared with intact skin, and contractile keratinocytes activation was disrupted in diabetic rat wounds.

CONCLUSIONS: Hyperglycaemia slightly slows wound healing in rats and impairs contractile keratinocytes activation. KEYWORDS: diabetes mellitus; streptozotocin; reparation; wound healing; immunohistochemistry; cytokeratin 10; cytokeratin 17 
Сахарный диабет (СД) называют неинфекционной пандемией: с 1980 г. численность больных во всем мире возросла с 4,7\% до 8,5\% [1], по текущим прогнозам, скорость увеличения числа больных диабетом будет только возрастать.

По мере течения СД развиваются осложнения, затрагивающие большинство органов и систем человека. В том числе, патологические факторы диабета влияют на процессы репарации, замедляя и нарушая восстановление структурной целостности тканей и органов. В наибольшей степени нарушения репарации клинически проявляются в виде синдрома диабетической стопы (СДС). Вследствие ангиопатии и/или нейропатии на коже дистальных участков конечностей развиваются длительное время незаживающие язвы, трудно поддающиеся лечению [2]. Механизмы нарушения репаративных процессов и ранозаживления при СД плохо изучены. Классические факторы повреждения при СД - конечные продукты гликозилирования, свободные радикалы, ишемия влияют на процессы репарации. Однако отдельную категорию составляют нарушения процессов регулирования пролиферации клеток: дисбаланс медиаторов, трофических факторов, нарушение ауторегуляции кератиноцитов [3]. Нарушения репарации в равной степени характерны для СД как 1, так и 2 типа. Несмотря на различия в патогенезе этих форм заболевания, клинические проявления, такие как СДС, различаются в меньшей степени. В связи с этим выделение ключевых факторов, отвечающих за нарушения репарации, требует использования экспериментальных моделей с выделенным ведущим патологическим звеном.

В современной литературе нет единого мнения относительно того, является ли гипергликемия основным фактором, вызывающим изменения в процессе заживления раны при СД. Okano и соавт. показали, что у мышей гипергликемия ухудшает барьерные свойства кожи [4]. Влияние гипергликемии на заживление раны, пролиферацию и дифференцировку кератиноцитов в моделях СД остается плохо изученным. В своей работе мы выбрали модель стрептозотоцин-индуцированного СД крыс, поскольку гипергликемия является в ней основным патологическим фактором при умеренной поддержке экзогенным инсулином [5]. Стрептозотоцин - вещество, токсичное для $\beta$-клеток поджелудочной железы. Однократная инъекция стрептозотоцина грызунам приводит к резкому снижению уровня инсулина и значительному увеличению концентрации глюкозы в крови, при этом метаболические и аутоиммунные факторы не участвуют в патогенезе развивающихся нарушений. Модели стрептозотоцинового СД хорошо изучены, и побочные токсические эффекты стрептозотоцина не считаются значимыми.

Выбор режима инсулинотерапии в значительной степени влияет на течение СД в экспериментальной модели. Отсутствие поддержки экзогенным инсулином, как мы обнаружили в предыдущих работах, существенно увеличивает смертность животных и не позволяет изучить отдаленные осложнения диабета. В лабораторной практике обычно используют человеческий инсулин, к которому крысы в большей степени резистентны, и дозы инсулина выглядят значительными по сравнению с человеческими. В целом считается, что ежедневные инъекции инсулина в дозах 1-3 Ед/кг не влияют на раз- витие осложнений в стрептозотоциновой модели СД, в то время как дозы 4-10 Ед/кг рассматривают в качестве терапевтических [6].

Одним из механизмов заживления ран на коже является изменение фенотипа дифференцированных кератиноцитов, приобретающих способность к миграции. Интерес представляет возможное изменение фенотипа кератиноцитов и соотношения кератиноцитов различных типов в процессе заживления раны при СД [7]. При заживлении острых ран у людей в течение первых 2 нед кератиноциты края раны преимущественно представлены активированным мигрирующим фенотипом, экспрессирующим такие маркеры, как цитокератины 14 и 16, и в лидирующей части длинного «языка» заживления не экспрессирующим цитокератины 2 и 10. Часть активированных клеток на более поздних этапах заживления начинает экспрессировать цитокератин 17 и приобретает способность к сокращению, что необходимо для стяжения краев раны. Данные об изменении этих процессов при СД неполные. Кератиноциты в краях диабетических язв активно экспрессируют маркеры миграции, например цитокератин 16, и по некоторым данным не экспрессируют цитокератины дифференцировки, однако, несмотря на это, не мигрируют для закрытия раневого дефекта [8].

Изменение фенотипов кератиноцитов в процессе заживления диабетической раны преимущественно описано у людей. Полученные сведения не позволяют судить о ключевых механизмах, вызывающих данные эффекты. В экспериментальных моделях репарации кожи при диабете изменения экспрессии цитокератинов показаны в одной работе и не полностью описаны [9]. Также не известно, изменяются ли процессы активации сократимых кератиноцитов, несущих маркеры цитокератина 17. В связи с этим в своей работе мы решили проверить, влияет ли гипергликемия на процесс изменения фенотипов кератиноцитов в процессе ранозаживления.

\section{ЦЕЛЬ}

Цель исследования: изучить влияние гипергликемии на заживление раны и дифференцировку кератиноцитов в модели стрептозотоцин-индуцированного СД крысы.

\section{МЕТОДЫ}

\section{Дизайн исследования}

В экспериментальное проспективное исследование вошли 87 самцов белых беспородных крыс массой

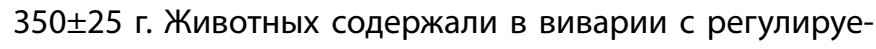
мым световым режимом, свободным доступом к пище и воде. В предварительном эксперименте шести животным диабет моделировали для подбора поддерживающей дозы инсулина. После верификации развития диабета подкожно в область холки крысам вводили инсулин детемир (Левемир ${ }^{\circledR}$ ), растворенный в физиологическом растворе в дозе от 0,1 Ед/кг до 20 Ед/кг в сутки утром в течение 7 дней. Уровень глюкозы в крови измеряли утром и вечером каждый день с помощью глюкометра OneTouch ${ }^{\circledast}$ Verio ${ }^{\circledast}(\mathrm{OOO}$ «Джонсон \& Джонсон») и сертифицированных тест-полосок (ООО «Джонсон \& Джонсон»). По полученным данным была выбрана поддерживающая 
доза инсулина 2 Ед/кг. Эта доза не влияла на уровень глюкозы в крови в течение дня.

Для моделирования СД крысам экспериментальной группы внутрибрюшинно однократно вводили стрептозотоцин в дозе 65 мг/кг, растворенный в холодном цитратном буфере $\left(\mathrm{pH}=4,5, \mathrm{t}=+4^{\circ} \mathrm{C}\right)$, крысам контрольной группы - только цитратный буфер.

\section{Критерии соответствия}

На 3-и сутки после введения стрептозотоцина оценивали концентрацию глюкозы в крови крыс. В экспериментальной группе животных с уровнем глюкозы менее 15 ммоль/л исключали из исследования, этот день считали точкой отсчета эксперимента.

\section{Условия проведения}

Исследование проведено на кафедре физиологии и общей патологии факультета фундаментальной медицины МГУ имени М.В. Ломоносова с соблюдением всех правил работы с лабораторными животными. Конфликт интересов при проведении исследования отсутствовал.

Продолжительность исследования

Продолжительность исследования составила 50-66 сут с момента введения стрептозотоцина или цитратного буфера. На 8-е, 16-е или 24-е сутки с момента нанесения раны производили забор гистологического материала

\section{Описание медицинского вмешательства}

С 3-х суток после введения стрептозотоцина начинали поддерживающие инъекции инсулина детемир (Левемир ${ }^{\circledR}$, Novo Nordisk, Дания) в дозе 2 Ед/кг. На 42-е сутки крысам, анестезированным диэтиловым эфиром, на спине под левой лопаткой по трафарету вырезали круглую рану диаметром 2 см. Кожу вокруг раны дезинфицировали растворами йода и хлоргексидина. В конечных точках на 8-е, 16-е или 24-е сутки после нанесения раны проводили забор гистологического материала. У крыс группы интактного контроля материал забирали на 4-м месяце жизни.

\section{Основной исход исследования}

Сравнительная динамика изменения размеров раны, морфолого-гистологическая характеристика ранозаживления и определение экспрессии цитокератинов 10 и 17 у крыс различных групп.

\section{Дополнительные исходы исследования}

Оценка уровня глюкозы и кетоновых тел в крови, изменение массы животных, оценка смертности, визуальная оценка состояния животных.

\section{Анализ в подгруппах}

В рамках общего протокола эксперимента крыс рандомизировали по массе. Две основные группы: экспериментальная (СД) и контрольная (цитратный буфер, ЦБ) были изначально разделены на три подгруппы по срокам забора материала после нанесения раны на кожу - 8-е, 16-е или 24-е сутки. В каждую подгруппу СД до начала эксперимента распределили 14 животных, в подгруппы ЦБ - по 10. В группу интактного контроля распределили 9 крыс.

\section{Методы регистрации исходов}

В течение всего времени исследования животных ежедневно взвешивали, еженедельно крысам измеряли концентрацию глюкозы в крови, как описано ранее. Измерение проводили утром до введения ежедневной дозы инсулина. Уровень кетоновых тел измеряли перед началом эксперимента, на 14-е, 28-е, 42-е сутки и в конечных точках с помощью кетометра Optimum Xceed ${ }^{\circledR}$ (Abbott Diabetes Care, США) и сертифицированных тест-полосок (Abbott Diabetes Care, США).

Площадь открытого раневого дефекта измеряли каждые 3-и сутки вплоть до точки забора гистологического материала. После полного закрытия раневой поверхности и формирования рубца раны считали зажившими.

Кожу вырезали вместе со всей площадью раны или сформировавшегося рубца, после чего, если дефект кожного покрова имел вытянутую форму, кожу разрезали поперек дефекта. Полученные образцы ткани фиксировали в формалине, дегидратировали и заливали парафином по стандартной методике. Ткань фиксировали таким образом, чтобы при нарезке микропрепаратов получить поперечные срезы раневого дефекта в центре раны и в участке неповрежденной кожи по краям. Для оценки общего состояния раны кожу окрашивали гематоксилином и эозином по стандартной методике. Для изучения процессов клеточной пролиферации и дифференцировки пользовались методом иммуногистохимии. Демаскировку антигенов проводили нагреванием в растворе цитратного буфера $(\mathrm{pH}=6,0)$, затем окрашивали срезы первичными антителами к цитокератину 10 (маркер стабильного клеточного фенотипа, кроличьи, ab9025, Abcam) и цитокератину 17 (маркер контрактильного фенотипа, мышиные, ab19067, Abcam). Для визуализации использовали вторичные антитела, связанные с пероксидазой хрена (козел против кролика (ab6721, Abcam) и козел против мыши (ab6789, Abcam)) и 3,3'-диаминобензидин (DAB) (ab64238, Abcam). Фоновую активность эндогенных пероксидаз снижали 3\% раствором пероксида водорода («ХимМед», РФ). Для контрокрашивания ядер клеток использовали гематоксилин («Биовитрум», РФ). Полученные микропрепараты изучали и фотографировали с помощью светового микроскопа Zeiss Imager A1 Axio (Zeiss, Германия) и программного обеспечения AxioVision 3,5 (Zeiss, Германия). Экспрессию маркеров оценивали качественно, в сравнении с общей морфологической картиной, и количественно. Для количественной оценки присутствия маркера в программе ImagePro (Media Cybernetica, США) оценивали среднюю долю окрашенных пикселей в пяти полях зрения по отношению к отрицательному контролю.

\section{Этическая экспертиза}

При работе с экспериментальными животными руководствовались приказом Министерства здравоохранения и социального развития Российской Федерации от 23 августа 2010 г. N 708н «Об утверждении Правил лабораторной практики». На проведение экспериментов было получено разрешение комиссии ФФМ МГУ имени М.В. Ломоносова по биоэтике NоБМЭ-12-17/-03 от 19.09.2017 г. 


\section{Статистический анализ}

Принципы расчета размера выборки: выборка рассчитана исходя из необходимого количества животных для адекватного осуществления иммуногистохимического исследования.

Методы статистического анализа данных. Статистический анализ проводили в программном пакете SPSS Statistics 23.0 (IBM, США). Нормальность распределения оценивали методом Колмогорова-Смирнова. При положительном результате данные представляли в виде среднее \pm стандартное отклонение, при отрицательном - в виде медиана \pm межквартильный размах. Выборки групп подпадали под критерии нормального распределения, выборки подгрупп не подпадали. Для оценки выживаемости использовали модель Кокса, позволяющую произвести корректную оценку при частичной неполноте данных. Для оценки значимости межгрупповых различий при изучении скорости ранозаживления, изменения массы и концентрации глюкозы и кетоновых тел в крови использовали дисперсионный анализ с повторными измерениями (repeated measures ANOVA). При сравнении полноты репарации ран в бинарных категориях использовали двусторонний точный тест Фишера. Для межгрупповых сравнений результатов иммуногистохимического окрашивания использовали многофакторный линейный анализ с построением смешанной линейной модели (допускает использование как нормальных, так и ненормальных выборок). Различия считали значимыми при $\mathrm{p}<0,05$.

\section{РЕЗУЛЬТАТЫ}

\section{Объекты (участники) исследования}

Предварительный эксперимент

Шести животным в предварительном эксперименте успешно индуцировали СД с уровнем глюкозы выше 30 ммоль/л. На протяжении нескольких недель крысам вводили инсулин в режиме эскалации дозы от 0,1 до 20 Ед/кг. Мы обнаружили, что дозы от 0,1 до 3Ед/кг не приводят к краткосрочной положительной динамике изменения массы и не снижают уровень глюкозы в крови в течение всех суток ниже уровня 30 ммоль/л. Доза 4 Ед/кг выраженно снижает вечернюю концентрацию глюкозы до 20 ммоль/л, доза 8 Ед/кг - вечернюю и утреннюю до 10-15 ммоль/л, а также вызывает положительную динамику массы тела. На основании полученных данных оптимальной поддерживающей дозой для данного исследования считали 2 Ед/кг инсулина подкожно в область холки.

Основной эксперимент

Стрептозотоцин ввели 42 животным, цитратный буфер - 30. На 3-и сутки после инициации диабета из эксперимента исключили 6 животных, 2 крысы умерли до этого момента, всего в группу СД вошли 34 крысы.

\section{Основные результаты исследования}

Средние значения размера раны в разные сроки эксперимента между группами СД и ЦБ значимо не отличались. Было замечено, что к концу эксперимента в группе ЦБ у всех животных рана полностью зажила, а в группе СД наблюдали вариабельность скорости ранозаживления. Поэтому животных разделили на две группы: относительно зажившие раны (площадь менее 15\% исходной площади) и незажившие раны (более 15\% исходной площади). Точный тест Фишера показал, что на 18-е сутки показатели размеров ран в экспериментальной и контрольной группах статистически значимо отличаются ( $p=0,046)$. На 21-е и 24-е сутки сохранялось похожее на 18-е сутки соотношение количества крыс с зажившими или незажившими ранами, но из-за уменьшения количества животных в группах различия оказались статистически незначимы (рис. 1).

Общая морфология кожи и процесса ранозаживления

В коже интактных крыс, окрашенной гематоксилином и эозином, в гомотопичной области нанесения раны у экспериментальных животных четко визуализируются базальный, шиповатый и зернистый слои (рис. 2A, в и г). Раневые дефекты у крыс в группах СД и ЦБ не имеют видимых морфологических отличий в окрашенных гематоксилином и эозином срезах (рис. 2Б, 2В). На 8-е сутки после нанесения раны большую часть поверхности закрывает грануляционная ткань, обильно инфильтрированная нейтрофилами, макрофагами и лимфоцитами (а). Поверх нее располагаются некротические массы. Регенерирующий край эпителия утолщен за счет большого числа клеток (б).
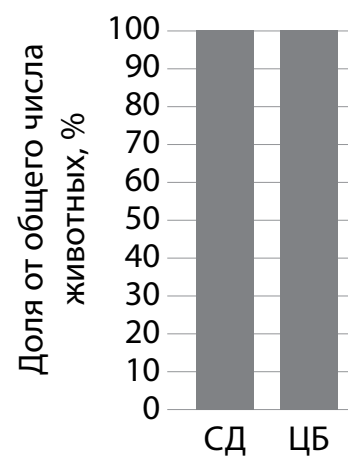

3-и сутки

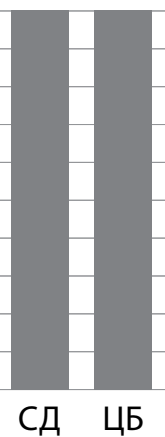

6-е сутки

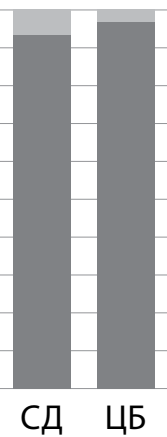

9-е сутки

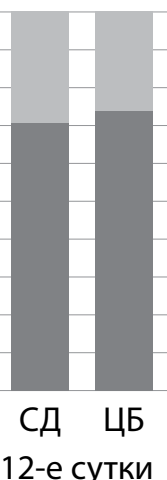

12-е сутки
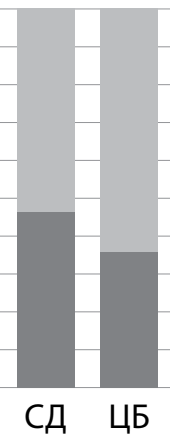

15-е сутки

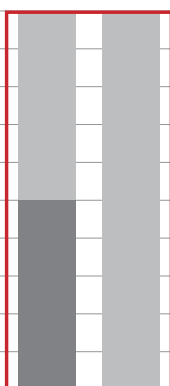

СД ЦБ

18-е сутки

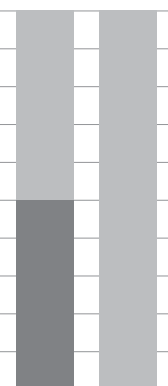

СД ЦБ

21-е сутки

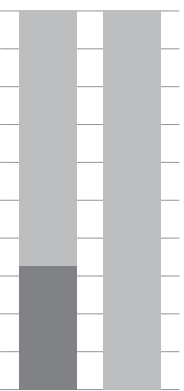

СД ЦБ

24-е сутки

$15 \%-100 \%$

$0 \%-15 \%$

Рис. 1. Динамика ранозаживления у крыс с СД и ЦБ. Доли крыс с площадями раны больше (темный столбик) или меньше (белый столбик) 15\% относительно исходной площади на 3-24-е сутки после нанесения раны; СД - сахарный диабет; ЦБ - цитратный буфер. Рамкой выделена временная точка со статистически значимыми различиями по точному тесту Фишера $(p=0,046)$. 


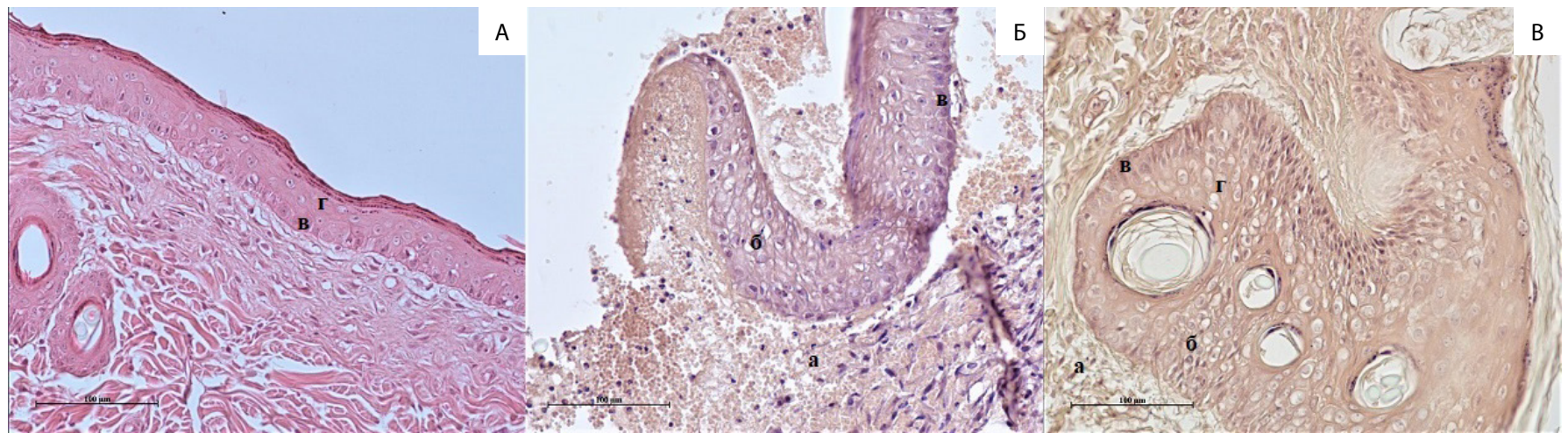

Рис. 2. Препараты кожи крысы, окраска гематоксилином и эозином, ×200. А - интактная кожа; Б - сахарный диабет, 8-е сутки заживления; В - группа цитратного буфера, 8-е сутки заживления; а - область воспаления и образования грануляционной ткани; б - регенерирующий край эпидермиса; в - базальный слой; г - шиповатый слой.

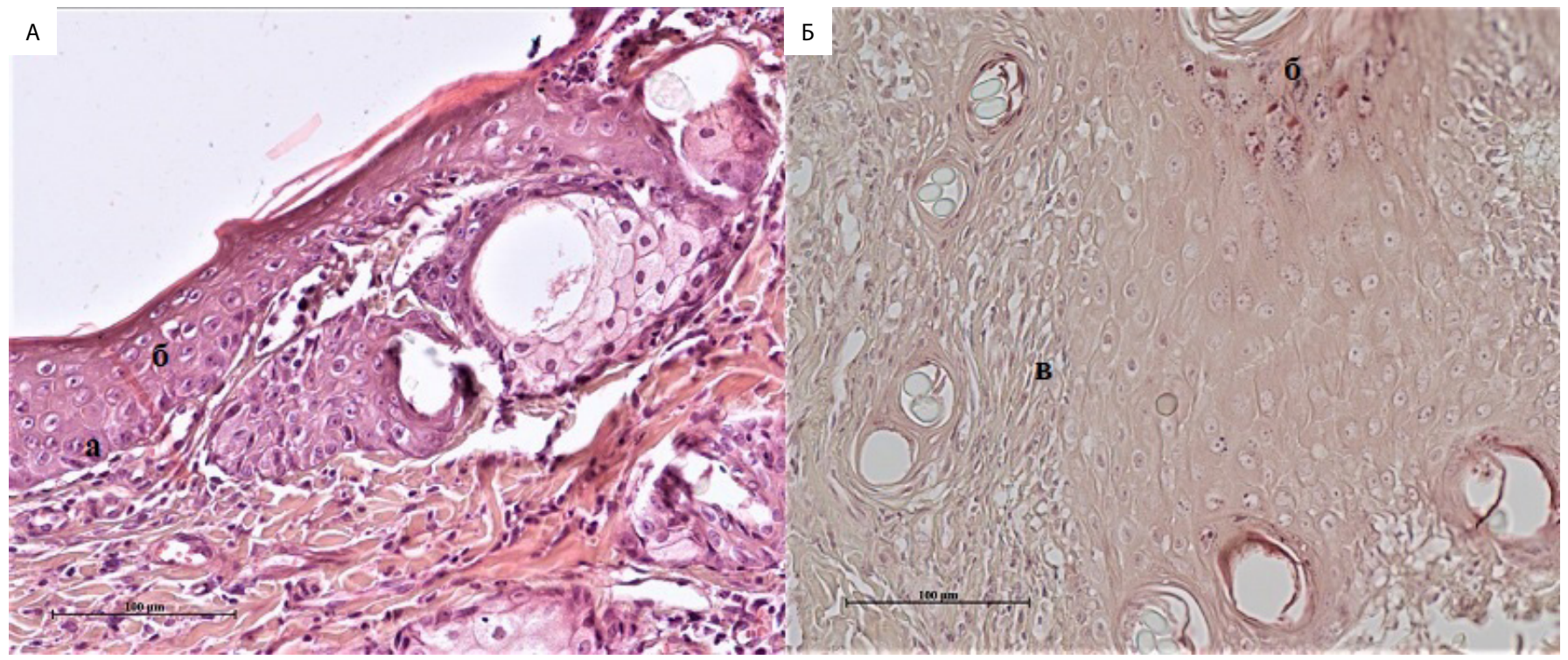

Рис. 3. Препараты кожи крысы, окраска гематоксилином и эозином, х400. А - группа сахарного диабета, 16-е сутки; Б - группа цитратного буфера, 16-е сутки; а - базальный слой; 6 - шиповатый слой; в - соединительнотканный рубец.

Визуально и по измеренной площади раны в двух группах в этот срок также не различались.

На 16-е сутки признаки острого повреждения исчезают. Поперечное сечение раны значительно уменьшается, у некоторых крыс в группе ЦБ завершается реэпителизация поверхности раны. В случае незавершенной эпителизации эпидермис в крае раны значительно утолщен, наблюдается прогрессивное формирование рубцовой ткани (рис. ЗА и 3Б, В). В этой временной точке количество животных с зажившими ранами между группами не различалось. На 24-е сутки сформировался волокнистый рубец, покрытый тонким слоем эпидермиса (рис. 4А и 4Б, в). У двух крыс в группе СД процесс эпителизации не завершился на 24-е сутки, при этом различия между группами на этом сроке не были статистически значимы.

\section{Экспрессия цитокератина 10}

Во всех исследуемых группах и интактном контроле кожа активно экспрессировала цитокератин 10 (см. рис. 5А). Базальный слой клеток преимущественно оказался не окрашен, а в верхних слоях эпидермиса цитокератин 10 экспрессировали все кератиноциты вне зависимости от группы. В растущем крае эпидермиса значительное число кератиноцитов экспрессировало данный маркер. Количественная оценка не выявила ста- тистически значимых различий между группами ЦБ и СД. В целом в крае раны экспрессия цитокератина 10 оказалась статистически значимо на 10,5\% выше, чем в коже интактных крыс (рис. 6).

Среди крыс с замедленной скоростью ранозаживления как в группе СД, так и в группе ЦБ наблюдали максимальные значения относительной плотности окрашивания на данный маркер, но в связи с небольшим количеством таких животных было невозможно дать корректную статистическую оценку данному результату. Можно заключить, что в крае раны крыс в процессе заживления сохранялось большое количество дифференцированных кератиноцитов, либо активированные клетки частично сохраняли филаменты дифференцированного типа.

\section{Экспрессия цитокератина 17}

Цитокератин 17 экспрессировали кератиноциты как в коже крыс интактного контроля, так и в группах СД и ЦБ (см. рис. 5Б). При этом на 16-е и 24-е сутки у крыс в контрольной группе плотность окрашивания статистически значимо увеличивалась почти в два раза, что соответствует этапу репарации раны, на котором активированные кератиноциты приобретают способность к сокращению, участвуя в стяжении краев раневого де- 


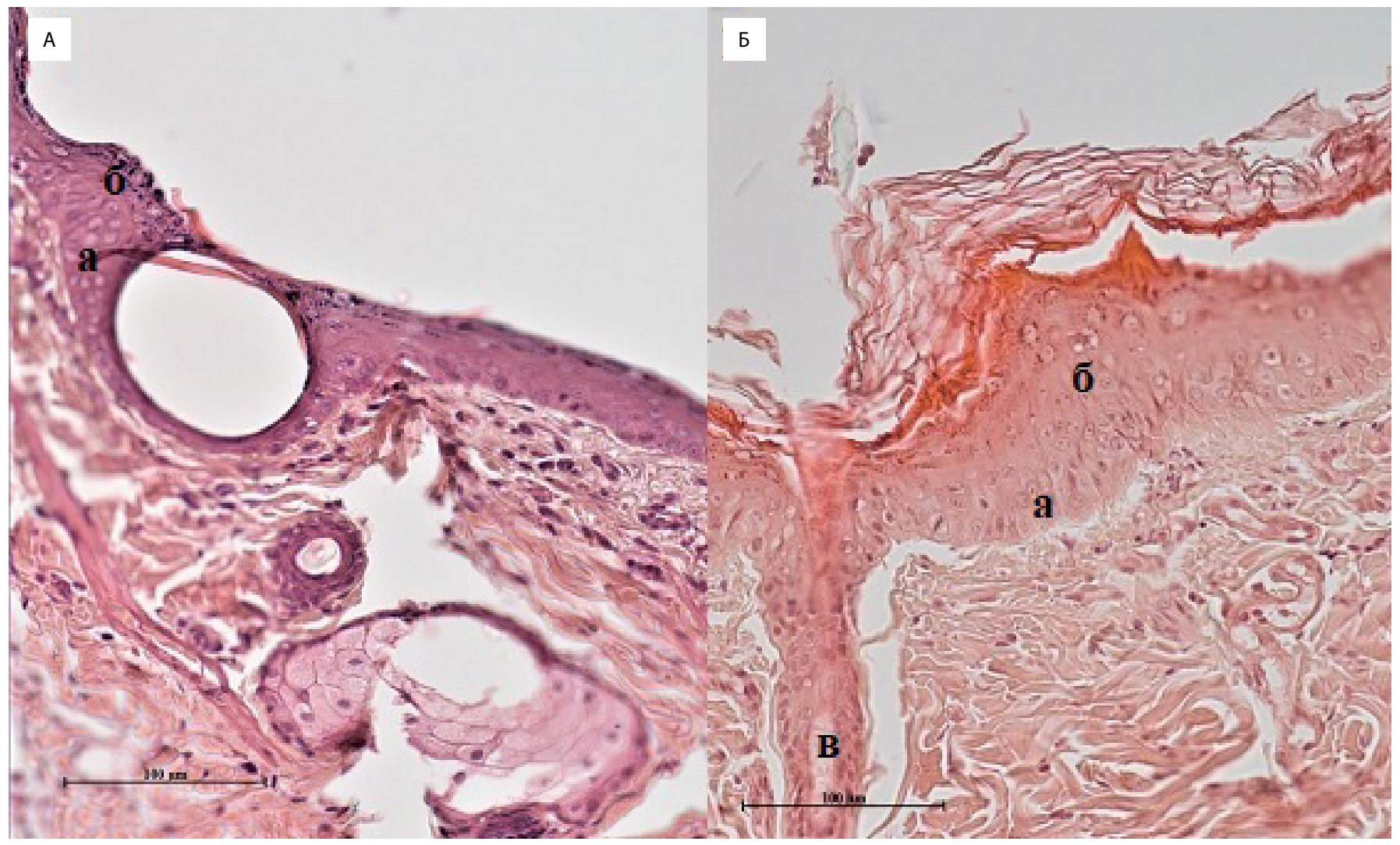

Рис. 4. Препараты кожи крысы, окраска гематоксилином и эозином, х800: А - группа сахарного диабета, 24-е сутки; Б - группа цитратного буфера, 24-е сутки; а - базальный слой; 6 - шиповатый слой; в - соединительнотканный рубец.

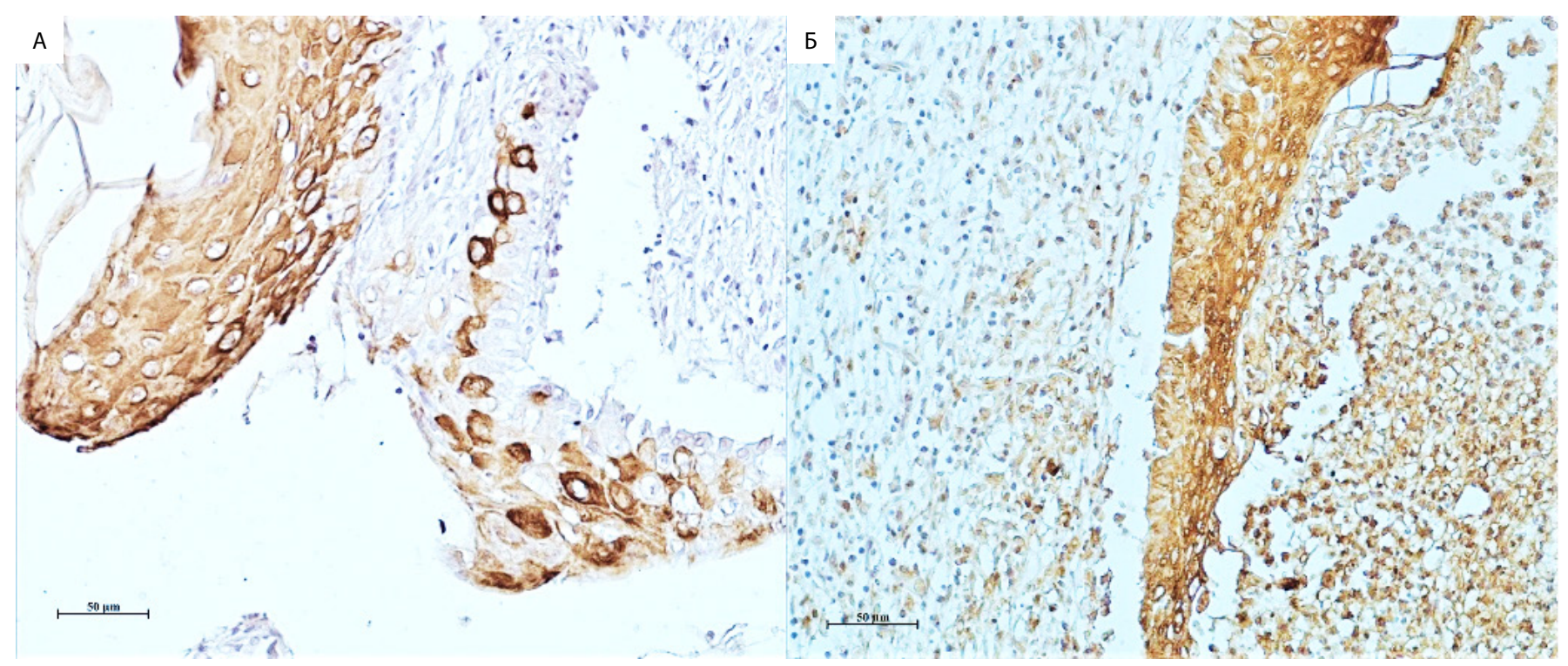

Рис. 5. Микропрепараты кожи крысы, метод иммуногистохимии, визуализация системой DАВ и контрокрашивание гематоксилином, х200. А - маркер цитокератина 10, группа СД8; Б - маркер цитокератина 17, группа СД8.

фекта во время формирования рубца и реэпителизации. В группе животных с СД такие изменения не происходили, что могло препятствовать заживлению и служить причиной неудавшейся репарации у двух крыс. Различия между группой ЦБ на 16-е и 24-е сутки и группой СД в соответствующие сроки, 8-ми сутками и интактным контролем были статистически значимы (см. рис. 7).
Дополнительные результаты исследования

В результате инъекции стрептозотоцина уровень глюкозы у крыс в группе СД в стартовой точке эксперимента был в 4-7 раз выше, чем у контрольных животных

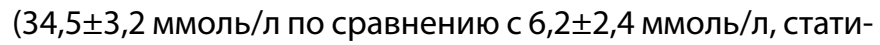
стически значимо во всех временных точках). Эти соотношения сохранялись в течение всего эксперимента. Уро- 


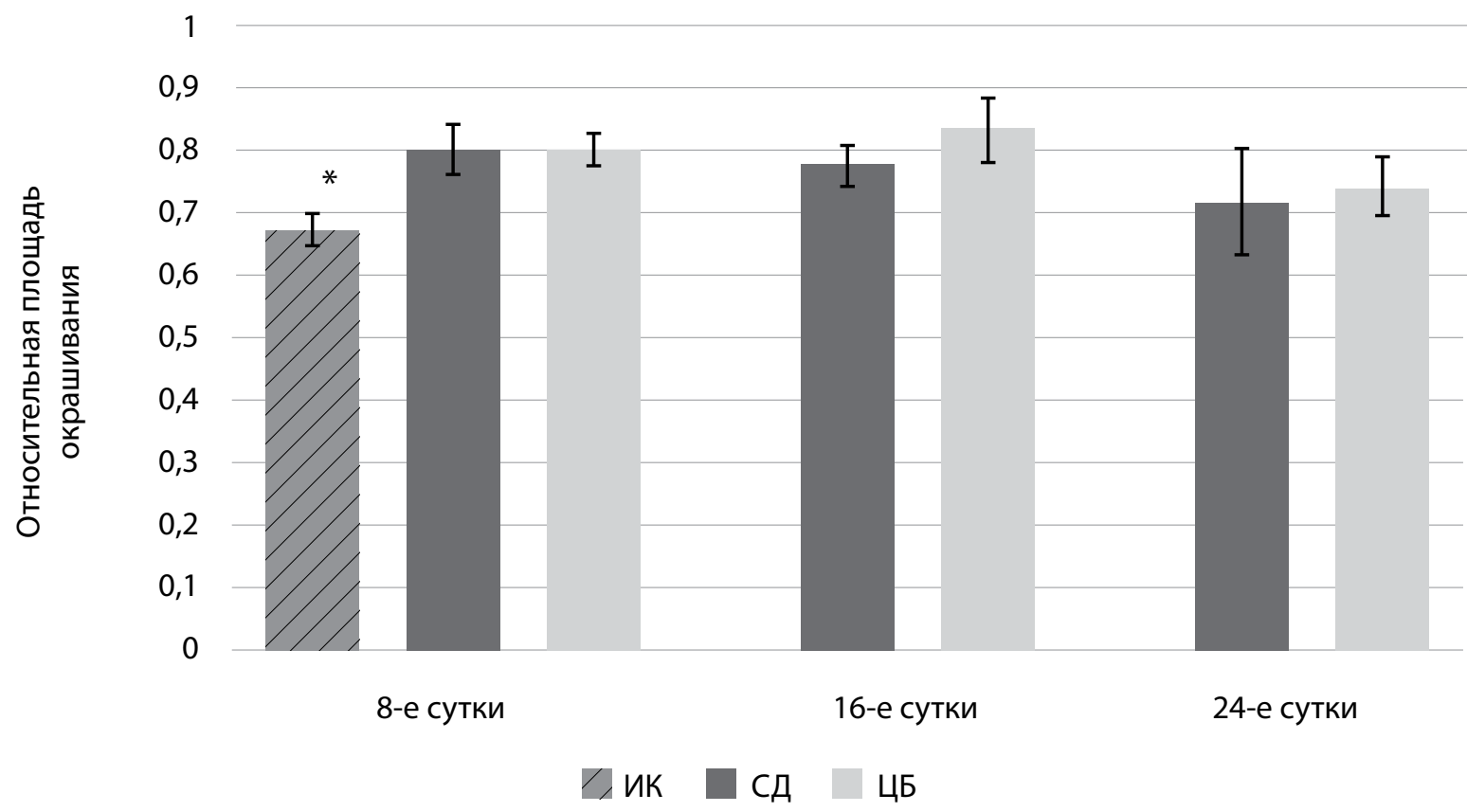

Рис. 6. Экспрессия цитокератина 10 в эпидермисе кожи края раны и эпидермисе кожи интактных крыс. * - р<0,05 по сравнению с другими группами, смешанная линейная модель. Данные представлены в виде медиана \pm межквартильный размах.

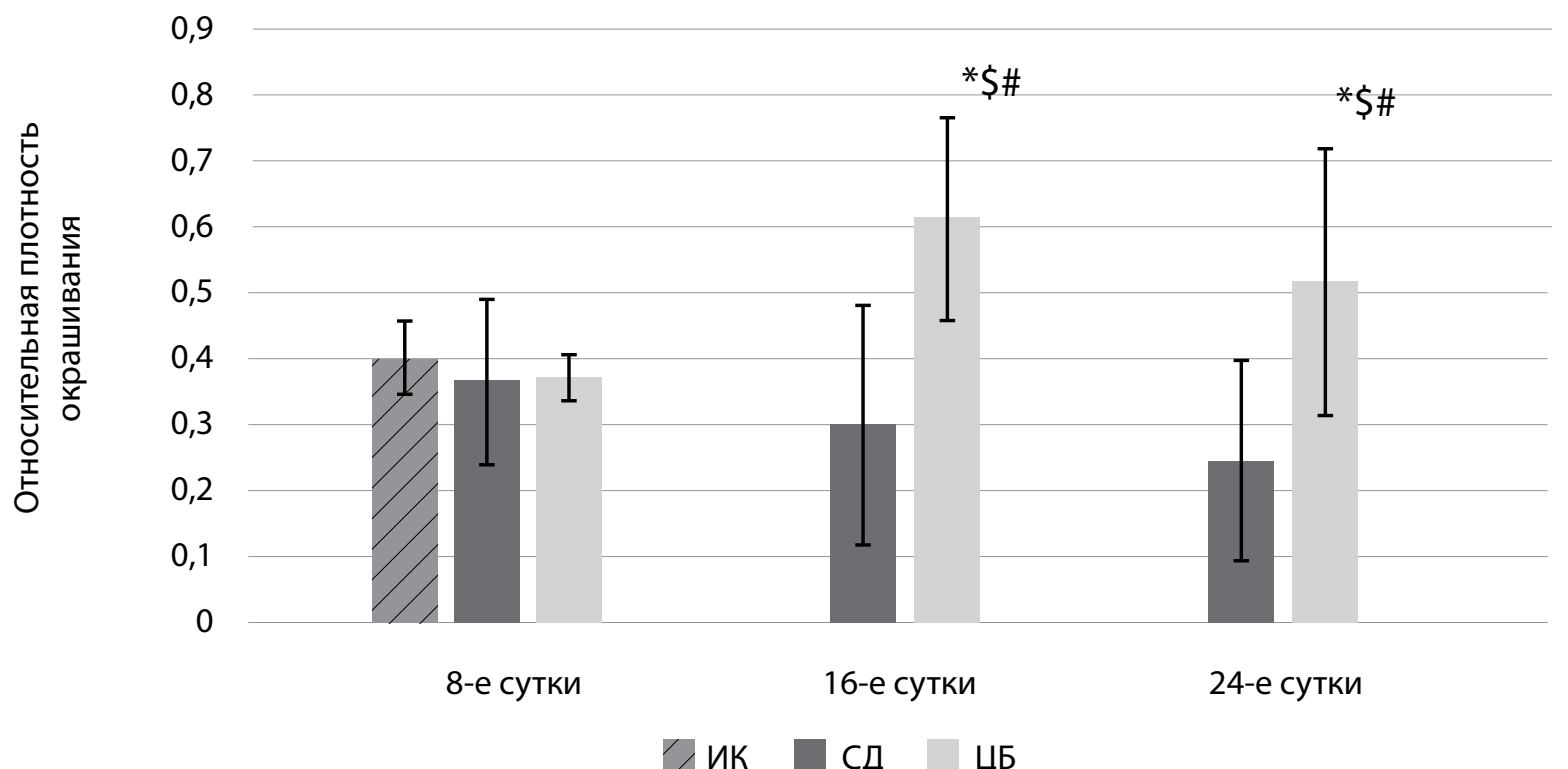

Рис. 7. Плотность окрашивания эпидермиса кожи края раны крыс антителами к цитокератину 17. Данные представлены в виде медиана \pm межквартильный размах. * - р<0,05 в сравнении с интактным контролем; $\$-$ р<0,05 в сравнении с 8-ми сутками; \# - р<0,05 в сравнении между группами сахарного диабета и цитратного буфера в одной временной точке, смешанная линейная модель.

вень кетоновых тел в среднем составил 0,9 0,3 ммоль/л, не изменялся по мере развития диабета и не отличался

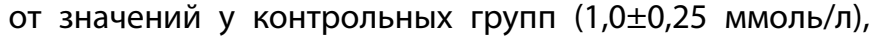
только у двух животных к концу эксперимента увеличившись до 2,3-2,5 ммоль/л. Также диабет, видимо, проявлялся полидипсией (потребление воды повысилось с 30-40 мл/сут до 150-250 мл/сут) и полиурией (отмечено субъективно по скорости намокания подстила). К концу эксперимента визуально крысы в группе СД отличались уменьшением жировой прослойки, сухостью кожи, наблюдали облысение, некроз кончика хвоста, помутнение глаз, общую неопрятность.

В ходе эксперимента в группе СД умерли 10 из 34 животных, в группе ЦБ - 5 крыс. Как с учетом, так и без учета летальных исходов, связанных с общей анестезией, вы- живаемость в двух группах значимо не отличалась ( $>>0,1$ в модели Кокса). При этом мы зафиксировали медленную отрицательную динамику массы тела животных в экспериментальной группе. Потеря массы за период эксперимента составила около 25\% по сравнению с исходным значением, в то время как крысы в группе ЦБ в среднем прибавили 20\% массы (рис. 8).

\section{Нежелательные явления}

Нежелательные явления у животных с СД, в том числе потеря массы до 25\% начальных значений, стойкая гипергликемия до 38 мМ, полидипсия, полиурия и другие внешние проявления связаны непосредственно с развитием и прогрессированием заболевания. Смертность животных в группах СД и ЦБ могла быть связана с общей анестезией. 


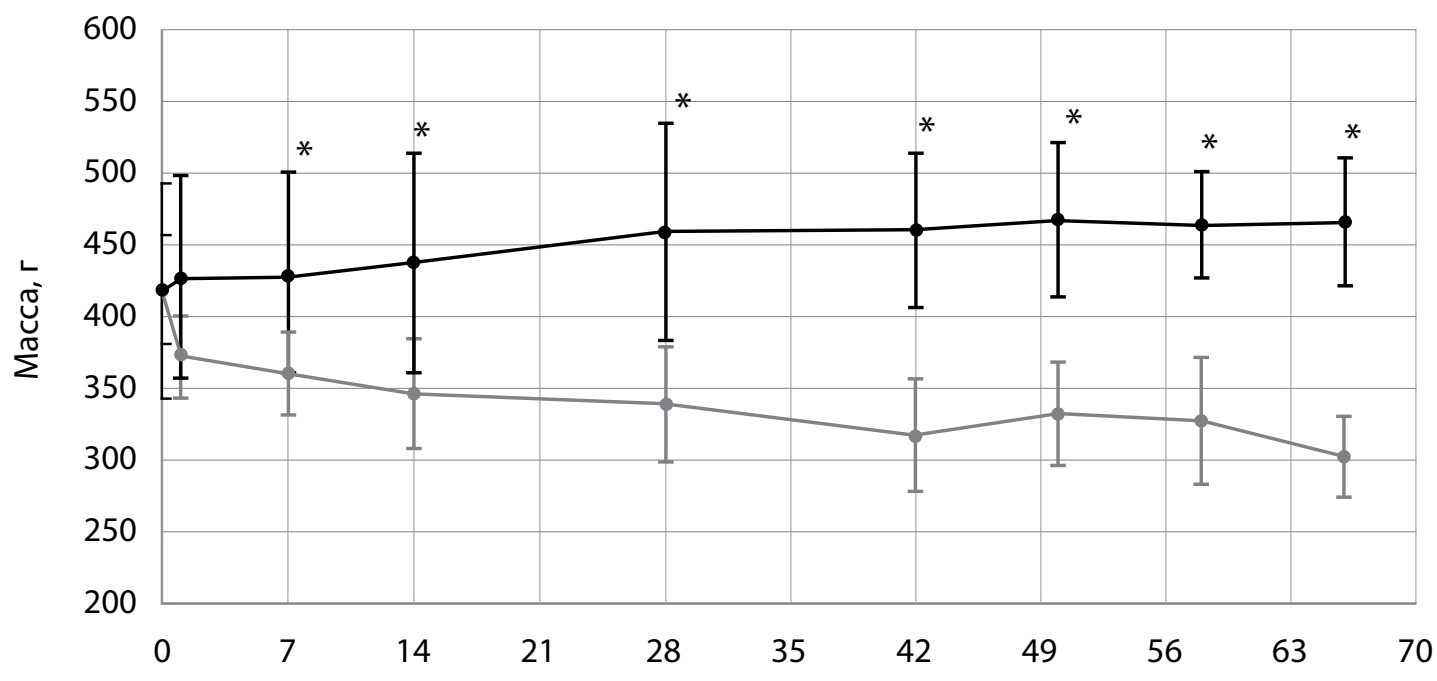

Сутки эксперимента

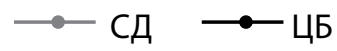

Рис. 8. Средние значения массы крыс в граммах \pm стандартное отклонение. СД - животные с сахарным диабетом, ЦБ; - контрольная группа. * - p<0,05 при сравнении между двумя группами, ANOVA.

\section{ОБСУЖДЕНИЕ}

\section{Резюме основного результата исследования}

В модели СД с выраженной гипергликемией по сравнению с контрольной группой статистически значимо не различалась полнота заживления раны. Только на 18-е сутки после нанесения различия в количестве животных с зажившими ранами были значимы. Относительная плотность окрашивания к цитокератину 10 в эпидермисе края раны не различалась между группами в течение эксперимента, а активация сократимых кератиноцитов, несущих маркер цитокератин 17, после нанесения раны была нарушена у крыс со стрептозотоциновым СД.

\section{Обсуждение основного результата исследования}

Стрептозотоциновая модель СД хорошо охарактеризована и используется для изучения различных аспектов развития заболевания. Стрептозотоцин - вещество с селективной токсичностью по отношению к $\beta$-клеткам поджелудочной железы. Многочисленные исследования показали, что стандартные дозы стрептозотоцина практически полностью разрушают клетки, синтезирующие инсулин, и приводят к высокому уровню гипергликемии [10]. Показано, что такие животные быстро теряют массу и погибают. Предварительный эксперимент позволил подобрать рабочую дозу инсулина детемир 2 Ед/кг/сут, которая при высоком (до 40 ммоль/л) уровне глюкозы поддерживала состояние животных на уровне, достаточном для развития хронических осложнений гипергликемии. Невысокие дозы инсулина (до 3-4 Ед/кг) считаются поддерживающими, большая часть литературных данных указывает на слабое влияние таких дозировок на течение СД [11]. Терапевтическими в стрептозотоциновой модели диабета крыс считаются дозы инсулина от 4 до 10 Ед/кг [12].

В основном эксперименте у животных группы СД развились характерные признаки СД, смертность животных была относительно низкой, а потеря массы тела - плав- ной. Мы не выявили увеличения уровня кетоновых тел в крови животных, что не объяснено полученными данными.

Известно, что гипергликемия является одним из ведущих факторов осложнений СД. Именно гипергликемия вызывает перераспределение жидкости в организме между клеточным, внеклеточным и сосудистым компартментами, активирует свободнорадикальные процессы, воспаление и ростовые процессы, приводит к повреждению клеток и тканей, в конечном итоге - к полиорганной недостаточности и гибели [13]. Нарушение репарации особенно заметно на кожных покровах. На ранних стадиях СД у пациентов нарушается заживление небольших раневых дефектов, затем формируются трофические язвы на нижних конечностях, наиболее тяжелым вариантом является формирование СДС [14]. Показано, что репаративные процессы в коже людей, страдающих СД, нарушены на молекулярном уровне. Кератиноциты экспрессируют меньшее количество ростовых факторов, таких, как VEGF и EGF [3], нормальное распределение фенотипических маркеров смещается в пользу высокодифференцированных покоящихся клеток [8]. Основываясь на этих данных, мы предположили, что именно длительная гипергликемия вызывает нарушение репарации кожи у крыс со стрептозотоциновым диабетом, связанное с изменением соотношения типов кератиноцитов при активации процессов ранозаживления, что до настоящего времени не было четко показано в существующих работах.

В нашем эксперименте у крыс с инъекцией ЦБ скорость заживления ран характеризовалась низким разбросом значений, у всех животных успешно завершился процесс репарации раны. В группе крыс с СД разброс значений скорости репарации был выше, что согласуется с литературными данными экспериментальных и клинических работ [15].

Уровень цитокератина 10 не различался между группами в течение эксперимента. Цитокератин 10 отражает 
зрелость кератиноцитов, его экспрессируют кератиноциты в верхних слоях эпидермиса, выполняющих механическую функцию. В крае раны количество кератиноцитов с данным маркером увеличилось в обеих группах без значимой разницы между животными с диабетом и здоровыми животными в контрольной группе. Данные литературы указывают, что при ранозаживлении кератиноциты края раны в течение 48 ч снижают экспрессию цитокератина 10, что необходимо для миграции и пролиферации. При СД в коже у людей экспрессия цитокератина 10 в целом снижена [16]. Полученные нами данные можно объяснить различными сроками изучения процесса репарации в указанных работах. Снижение экспрессии цитокератина 10 описано в первые несколько суток после нанесения раны, в настоящем исследовании показано, что на поздних этапах заживления количество цитокератина 10 в эпидермисе больше, чем в интактной коже, что может быть связано с перераспределением дифференцированных кератиноцитов.

Цитокератин 17 - маркер способных к сокращению активированных кератиноцитов. Несущие его клетки участвуют в репарации. Цитокератин 17 обнаружен в разных слоях эпидермиса [11]. Роль цитокератина 17 в процессе репарации кожи в настоящее время не до конца изучена, в целом изменения фенотипа кератиноцитов при СД и в его моделях не описаны [17]. Полученные данные могут свидетельствовать о важной роли цитокератина 17 в репарации кожи и нарушении активации сократимых кератиноцитов при СД под действием гипергликемии.

\section{Ограничения исследования}

Мы не обнаружили значительных различий в распределении цитокератина 10 в крае раны в исследованных временных точках у крыс с СД и животных из контрольной группы. Возможно, они ограничены только начальными стадиями процесса ранозаживления или не наблюдаются в целом. Вероятно, необходимо изучение процессов ранозаживления у крыс с более длительным течением СД. Общая динамика изменения экспрессии цитокератина 10 в крае раны по сравнению с кожей интактных животных соответствует известным механизмам ранозаживления.

\section{ЗАКЛЮЧЕНИЕ}

Таким образом, полученные данные свидетельствуют о том, что высокий уровень глюкозы на данном сроке развития СД у стрептозотоциновых крыс не вызывает существенного снижения скорости ранозаживления, но изменяет активацию сократимых кератиноцитов. Среди группы крыс с диабетом выделилась подгруппа животных со сниженной скоростью ранозаживления, возможно, эти нарушения связаны с дефектами смены фенотипов кератиноцитов. Для выявления тонких механизмов регуляции ранозаживления при СД необходимо проведение дополнительных исследований с подробной характеристикой кератиноцитов в области раны, а также определение их секреторной активности.

\section{ДОПОЛНИТЕЛЬНАЯ ИНФОРМАЦИЯ}

Источник финансирования. Работа поддержана Российским научным фондом (грант РНФ 16-15-10365)

Конфликт интересов. Авторы декларируют отсутствие явных и потенциальных конфликтов интересов, связанных с публикацией настоящей статьи.

Участие авторов: Иванов Е.В. - экспериментальная работа по взвешиванию крыс, измерению уровней глюкозы и кетоновых тел, моделирование сахарного диабета, моделирование и измерение раны, гистологические исследования, анализ результатов, участие в написании текста статьи; Морозова М.П. - экспериментальная работа по взвешиванию крыс, измерению уровней глюкозы и кетоновых тел, моделирование сахарного диабета, измерение раны, написание текста статьи; Ржавина Е.М. - экспериментальная работа по взвешиванию крыс, измерению уровней глюкозы и кетоновых тел, моделирование сахарного диабета, написание текста статьи; Горбачева А.М. - гистологические исследования, анализ результатов, участие в написании текста статьи; Гаврилова С.А. - разработка концепции и дизайна исследования, координация эксперимента, моделирование и измерение раны, участие в написании текста статьи; Ердяков А.К. - участие в написании текста статьи, подготовка статьи к публикации; Галстян Г.Р. - концепция исследования, участие в написании текста статьи; Кошелев В.Б. - координация эксперимента, концепция исследования, участие в написании текста статьи. Все авторы внесли значимый вклад в проведение исследования и подготовку статьи, прочли и одобрили финальную версию статьи перед публикацией.

\section{СПИСОК ЛИТЕРАТУРЫ | REFERENCES}

1. WHO. Global report on diabetes [Internet]. WHO; 2016. Available from: https://apps.who.int/iris/bitstream/ handle/10665/204871/9789241565257_eng.pdf?sequence=1

2. Mendes AL, Miot HA, Haddad V Jr. Diabetes mellitus and the skin. An Bras Dermatol. 2017;92(1):8-20. doi: https://doi.org/10.1590/abd1806-4841.20175514

3. Wang CJ, Ko JY, Kuo YR, et al. Molecular changes in diabetic foot ulcers. Diabetes Res Clin Pract. 2011;94(1):105-110. doi: https://doi.org/10.1016/j.diabres.2011.06.016

4. Okano J, Kojima H, Katagi M, et al. Hyperglycemia induces skin barrier dysfunctions with impairment of epidermal integrity in non-wounded skin of type 1 diabetic mice. PloS One. 2016;11(11):e0166215. doi: https://doi.org/10.1371/journal.pone.0166215

5. Brito-Casillas Y, Melián C, Wägner AM. [Study of the pathogenesis and treatment of diabetes mellitus through animal models. (In English, Spanish)]. Endocrinol Nutr. 2016;63(7):345-353. doi: https://doi.org/10.1016/j.endonu.2016.03.011
6. Pepper AR, Gall C, Mazzuca DM, et al. Diabetic rats and mice are resistant to porcine and human insulin: flawed experimental models for testing islet xenografts. Xenotransplantation. 2009;16(6):502-510. doi: https://doi.org/10.1111/j.1399-3089.2009.00548.x

7. Demidova-Rice TN, Hamblin MR, Herman IM. Acute and impaired wound healing: pathophysiology and current methods for drug delivery, part 1: normal and chronic wounds: biology, causes, and approaches to care. Adv Skin Wound Care. 2012;25(7):304-314. doi: https://doi.org/10.1097/01.ASW.0000416006.55218.d0

8. Usui ML, Mansbridge JN, Carter WG, et al. Keratinocyte migration, proliferation, and differentiation in chronic ulcers from patients with diabetes and normal wounds. J Histochem Cytochem. 2008;56(7):687-696. doi: https://doi.org/10.1369/jhc.2008.951194

9. Ahmed RR, Mahmoud A, Ahmed OM, et al. Up-regulation of Hsp72 and keratin 16 mediates wound healing in streptozotocin diabetic rats. Biol Res. 2015;48:54 doi: https://doi.org/10.1186/s40659-015-0044-5 
10. Lenzen S. The mechanisms of alloxan- and streptozotocininduced diabetes. Diabetologia. 2008;51(2):216-226. doi: https://doi.org/10.1007/s00125-007-0886-7

11. Biessels GJ, Bril V, Calcutt NA, et al. Phenotyping animal models of diabetic neuropathy: a consensus statement of the diabetic neuropathy study group of the EASD (Neurodiab). J Peripher Nerv Syst. 2014:19(2):77-87. doi: https://doi.org/10.1111/jns5.12072

12. Oliveira FS, Nessler RA, Castania JA, et al. Ultrastructural and morphometric alterations in the aortic depressor nerve of rats due to long term experimental diabetes: effects of insulin treatment. Brain Res. 2013;1491:197-203. doi: https://doi.org/10.1016/j.brainres.2012.10.054

13. Pichu S, Patel BM, Apparsundaram S, Goyal RK. Role of biomarkers in predicting diabetes complications with special reference to diabetic foot ulcers. Biomark Med. 2017:11(4):377-388. doi: https://doi.org/10.2217/bmm-2016-0205

14. Lim JZ, Ng NS, Thomas C. Prevention and treatment of diabetic foot ulcers. J R Soc Med. 2017;110(3):104-109. doi: https://doi.org/10.1177/0141076816688346

15. Noor S, Zubair M, Ahmad J. Diabetic foot ulcer — a review on pathophysiology, classification and microbial etiology. Diabetes Metab Syndr. 2015;9(3):192-199. doi: https://doi.org/10.1016/j.dsx.2015.04.007

16. Freedberg IM, Tomic-Canic M, Komine M, Blumenberg M. Keratins and the keratinocyte activation cycle. J Invest Dermatol. 2001;116(5):633640. doi: https://doi.org/10.1046/j.1523-1747.2001.01327.x

17. Blakytny R, Jude EB. Altered molecular mechanisms of diabetic foot ulcers. Int J Low Extrem Wounds. 2009;8(2):95-104. doi: https://doi.org/10.1177/1534734609337151

\section{ИНФОРМАЦИЯ ОБ АВТОРАХ [AUTHORS INFO]}

*Ердяков Алексей Константинович, к.б.н. [Aleksei K. Erdiakov, PhD]; адрес: Россия, 119991, Москва, Ломоносовский пр-т, д. 27, корп. 1 [address: 27-1 Lomonosov ave., 119991, Moscow, Russian Federation]; ORCID: https://orcid.org/0000-0002-2208-5733; eLibrary SPIN: 3983-4010; e-mail: alexey.erdyakov@ya.ru

Иванов Евгений Викторович [Evgeniy V. Ivanov, MD]; ORCID: https://orcid.org/0000-0002-3382-4458; eLibrary SPIN: 8191-5630; e-mail: ivanovev101@gmail.com Морозова Мария Павловна, к.б.н. [Maria P. Morozova, PhD]; ORCID: https://orcid.org/0000-0002-7829-4753; eLibrary SPIN: 2018-3418; e-mail: mormasha@gmail.com

Ржавина Екатерина Михайловна [Ekaterina M. Rzhavina]; ORCID: https://orcid.org/0000-0002-9485-3068; eLibrary SPIN: 4202-2107; e-mail: klochikhinaem@gmail.com Горбачева Анна Максимовна [Anna M. Gorbacheva, MD]; ORCID: http://orcid.org/0000-0001-6581-4521; eLibrary SPIN: 9815-7509; e-mail: ann.gorbachewa@yandex.ru

Гаврилова Светлана Анатольевна, к.б.н., доцент [Svetlana A. Gavrilova, PhD in Biology, associate professor]; ORCID: https://orcid.org/0000-0002-8776-6062; eLibrary SPIN: 9212-1137; e-mail: sgavrilova@mail.ru.

Галстян Гагик Радикович, д.м.H., професcop [Gagik R. Galstyan, MD, PhD, D. Sc., Professor]; ORCID: https://orcid.org/0000-0001-6581-4521; eLibrary SPIN: 9815-7509; e-mail: galstyangagik964@gmail.com Кошелев Владимир Борисович, д.б.н., профессор [Vladimir B. Koshelev, PhD in Biology, Professor]; ORCID: https://orcid.org/0000-0003-0354-5607; eLibrary SPIN: 2358-7046; e-mail: KoshelevVladimir1953@yandex.ru

\section{ЦИТИРОВАТЬ:}

Иванов Е.В., Морозова М.П., Ржавина Е.М., Горбачева А.М., Гаврилова С.А., Ердяков А.К., Галстян Г.Р., Кошелев В.Б. Пролиферация кератиноцитов и заживление раны в стрептозотоциновой модели сахарного диабета крысы с выраженной гипергликемией // Сахарный диабет. — 2020. - Т. 23. — №1. — C. 19-28. doi: https://doi.org/10.14341/DM10071

\section{TO CITE THIS ARTICLE:}

Ivanov EV, Morozova MP, Rzhavina EM, Gorbacheva AM, Gavrilova SA, Erdiakov AK, Galstyan GR, Koshelev VB. Keratinocytes proliferation and wound healing in rats with streptozotocin - induced diabetes and severe hyperglycemia. Diabetes Mellitus. 2020;23(1):19-28. doi: https://doi.org/10.14341/DM10071 